\title{
Oncostatin M Measurement
}

National Cancer Institute

\section{Source}

National Cancer Institute. Oncostatin M Measurement. NCI Thesaurus. Code C132377.

The determination of the amount of oncostatin $\mathrm{M}$ in a biological sample. 